\title{
Influence of thermal exposure on microstructure and stress rupture properties of a new Re- containing single crystal Ni-based superalloy
}

\author{
*Chen-guang Liu, Yun-song Zhao, Jian Zhang, Ding-zhong Tang, Chun-zhi Li, and Zhen-ye Zhao \\ Science and Technology on Advanced High Temperature Structural Materials Laboratory, Beijing Institute of Aeronautical Materials, Beijing \\ 100095, China
}

\begin{abstract}
In this study, the long-term thermal microstructural stability and related stress rupture lives of a new Re-containing Ni-based single-crystal superalloy, DD11, were investigated after high-temperature exposure for different lengths of time. The results show that the $\gamma^{\prime}$ precipitates retained a cuboidal morphology and the $\gamma^{\prime}$ size increased after short thermal exposure for $50 \mathrm{~h}$ at $1,070{ }^{\circ} \mathrm{C}$. As the thermal exposure time was prolonged to $500 \mathrm{~h}$, the cuboidal $\gamma^{\prime}$ gradually changed into irregular raft-like morphology due to particles coalescence, and the morphology of the microstructure was almost unchanged after further thermal exposure up to 3,000 h. The stress rupture experiments at $1,070{ }^{\circ} \mathrm{C}$ and a tensile stress of $140 \mathrm{MPa}$ showed that the rupture lives increased significantly after thermal exposure for $50 \mathrm{~h}$ and dropped dramatically with increasing exposure time up to $500 \mathrm{~h}$ but decreased slowly after exposure for more than $500 \mathrm{~h}$. These results imply that stress rupture properties did not decrease when the $\gamma^{\prime}$ remained cuboidal but degraded to different extents during the $\gamma^{\prime}$ coarsening process. The coarsening of the $\gamma^{\prime}$ precipitates and change in morphology were regarded as the main factors leading to the degradation of the stress rupture lives. This study provides fundamental information on the high-temperature longterm microstructural stability and mechanical performance, which will be of great help for DD11 alloy optimization and engineering aeroengine applications.
\end{abstract}

Key words: Ni-based superalloy; thermal exposure; microstructure; coarsening; stress-rupture properties CLC numbers: TG132.3 3 Document code: A Article ID: 1672-6421(2018)01-051-07

\begin{abstract}
ingle-crystal (SC) nickel-based superalloys are widely used as turbine blade materials because of their excellent mechanical properties ${ }^{[1]}$. The superior high-temperature behavior is mainly attributed to the two-phase microstructure consisting of a $\gamma$-matrix (Ni) and a large volume fraction of $\gamma^{\prime}$-precipitates $\left(\mathrm{Ni}_{3} \mathrm{Al}\right)$ in the range of $65 \%$ to $70 \%$. Within this optimum $\gamma^{\prime}$ volume fraction range, the strengthening effect of the $\gamma^{\prime}$-precipitates depends largely on their size and morphology ${ }^{[2-4]}$.

During high-temperature service, the $\gamma / \gamma^{\prime}$ two-phase microstructure will be degraded due to a coarsening process, during which the $\gamma^{\prime}$ precipitates evolve from cuboidal into plate-like morphology, accompanied by a loss of the precipitate coherency and deterioration
\end{abstract}

\section{*Chen-guang Liu}

Male, born in 1981, Doctor candidate. Research interests: microstructure analysis, high-temperature mechanical performance and casting process control of nickel-based single crystal superalloys and turbine blades.

E-mail: Icgsuperalloy@163.com

Received: 2017-03-21; Accepted: 2017-09-10 of the mechanical properties ${ }^{[5,6]}$. The driving forces for coarsening are the reduction of the $\gamma / \gamma^{\prime}$ interfacial area, the decrease of the lattice mismatch strain, and reduction of the modulus misfit ${ }^{[7,8]}$. The $\gamma^{\prime}$ coarsening process is strongly affected by service temperature and time and vary with compositional differences in Ni-based superalloys due to the diffusion-related coarsening process. Since single-crystal blades and vanes work for a long time at elevated temperatures during service, a reliable mechanical performance is essential for engineering application as gas turbine blades. Consequently, the stability of the microstructure and mechanical properties after long-term exposure at elevated temperature have been extensively investigated in all of the widely used single-crystal Ni-based superalloys, such as CMSX-4 and CMSX-10 $0^{[9,10]}$.

Recently, a second-generation single-crystal superalloy, DD11, with 3wt.\% Re has been developed by Beijing Institute of Aeronautical Materials for aeroengine blade applications. DD11 has shown excellent high-temperature tensile and stress rupture properties and is a promising blade material ${ }^{[11]}$. However, 
little is known about the high-temperature microstructural evolution and resultant mechanical properties, in particular for long-term thermal exposure at temperatures close to the service limiting conditions. In this study, microstructural stability during thermal exposure for up to $3,000 \mathrm{~h}$ at $1,070{ }^{\circ} \mathrm{C}$ was evaluated. Stress rupture properties and rupture behavior after thermal exposure for different times were explored to understand the effects of microstructural changes on the mechanical properties. This study provides fundamental information on the hightemperature long-term microstructural stability and mechanical performance of DD11 for alloy optimization and engineering aeroengine applications.

\section{Experiment}

The chemical composition of single-crystal superalloy DD11 is listed in Table 1. Directionally solidified single-crystal bars with a diameter of $15 \mathrm{~mm}$ and length of $200 \mathrm{~mm}$ were produced in investment casting cluster molds. The samples were processed using standard high-gradient industry practices in a Bridgemantype withdrawal furnace in the [001] direction at a constant withdrawal rate of $3 \mathrm{~mm} \cdot \mathrm{min}^{-1}$. The Laue back-reflection technique was used to determine the longitudinal orientation of the single-crystal bars. Single-crystal bars with orientation within $10^{\circ}$ of [001] were used in this study.

Table 1: Chemical compositions (wt.\%) of single-crystal superalloy DD11

\begin{tabular}{cccccccccccc} 
Cr & Co & Mo & W & Re & Ta & Nb & Al & Hf & Ni \\
\hline 4.0 & 8.0 & 2.0 & 7.0 & 3.0 & 7.0 & 0.5 & 6.0 & 0.2 & Bal.
\end{tabular}

Full heat treatments of the single-crystal bars were performed according to the following standard procedure: $1,290^{\circ} \mathrm{C} / 1 \mathrm{~h}$ $+1,300^{\circ} \mathrm{C} / 1 \mathrm{~h}+1,310^{\circ} \mathrm{C} / 2 \mathrm{~h}+1,318^{\circ} \mathrm{C} / 6 \mathrm{~h}$ (air cooling) + $1,130^{\circ} \mathrm{C} / 4 \mathrm{~h}$ (air cooling) $+870^{\circ} \mathrm{C} / 32 \mathrm{~h}$ (air cooling). After heat treatment, each single-crystal bar was machined into two cylindrical and threaded stress rupture test bars. The gage section of the test bar was $5 \mathrm{~mm}$ in diameter and $25 \mathrm{~mm}$ in length, and the overall sample length was about $60 \mathrm{~mm}$. The remainders of the single-crystal bars were subjected to longterm unstressed high-temperature exposure to determine the microstructural stability of the alloy. The thermal exposure of the bars was performed at $1,070{ }^{\circ} \mathrm{C}$ for $20,50,100,200,300$, $500,1,000$, and $3,000 \mathrm{~h}$, respectively (Table 2). After thermal exposure, samples were cut from the single-crystal bars by electric wire-cutting machining. The stress rupture samples were machined into threaded test bars. Constant load stress rupture testing was conducted at $1,070{ }^{\circ} \mathrm{C}$ under a tensile stress of $140 \mathrm{MPa}$. The tests were performed until the rupture of the specimens occurred. The fracture surfaces were characterized by a scanning electron microscopy (SEM).

In order to dissolve the $\gamma^{\prime}$ phase, the samples were mechanically polished and etched with an etchant $\left(5 \mathrm{~g} \mathrm{CuSO}_{4}+\right.$ $25 \mathrm{~mL} \mathrm{HCl}+20 \mathrm{~mL} \mathrm{H}_{2} \mathrm{O}+5 \mathrm{~mL} \mathrm{H}_{2} \mathrm{SO}_{4}$ ). The microstructures

Table 2: Conditions of thermal exposure and stress rupture test

\begin{tabular}{|c|c|c|c|}
\hline Sample & $\begin{array}{l}\text { Thermal exposure } \\
\text { temperature }\left({ }^{\circ} \mathrm{C}\right)\end{array}$ & $\begin{array}{c}\text { Thermal } \\
\text { exposure time (h) }\end{array}$ & $\begin{array}{l}\text { Condition of } \\
\text { stress rupture }\end{array}$ \\
\hline 1 & \multicolumn{2}{|c|}{ Baseline } & \multirow{9}{*}{$1,070^{\circ} \mathrm{C} / 140 \mathrm{MPa}$} \\
\hline 2 & \multirow{8}{*}{1,070} & 20 & \\
\hline 3 & & 50 & \\
\hline 4 & & 100 & \\
\hline 5 & & 200 & \\
\hline 6 & & 300 & \\
\hline 7 & & 500 & \\
\hline 8 & & 1,000 & \\
\hline 9 & & 3,000 & \\
\hline
\end{tabular}

were examined by SEM. Images were taken of the secondary dendrite arms, which represent the greater part of the microstructure. The morphology of the dislocation in the $\gamma / \gamma^{\prime}$ interface was examined by transmission electron microscopy (TEM). Transmission microscopy foils were sectioned from the (100) crystal plane and thinned by the twin jet polishing technique using an electrolyte consisting of $10 \%$ perchloric acid and $90 \%$ ethanol

\section{Results and discussion}

\subsection{Microstructure}

The initial microstructures of single-crystal superalloy DD11 after full heat treatment are presented in Fig. 1. The $\gamma^{\prime}$ precipitates exhibited a uniform distribution and cuboidal morphology with an average edge length of about $370 \mathrm{~nm}$, and were aligned along $\{100\}$ habit planes and separated by thin $\gamma$ channels with a mean thickness of about $40 \mathrm{~nm}$. The volume fraction of the $\gamma^{\prime}$ precipitates was about $68 \%$, while no other phase was observed in addition to the $\gamma$ and $\gamma^{\prime}$ phases. The $\gamma /$ $\gamma^{\prime}$ two-phase microstructures from both bottom and top of each single-crystal bar were examined, and no apparent variation was found among them.

The microstructures of single-crystal superalloy DD11 subjected to long-term thermal exposure at $1,070{ }^{\circ} \mathrm{C}$ from 20 to $3,000 \mathrm{~h}$ are shown in Fig. 2, where the continuous growth of both the $\gamma$ channels width and the $\gamma^{\prime}$ precipitate size as well as the morphological change of $\gamma^{\prime}$ precipitates can be seen. Compared with the initial microstructure, the morphology of $\gamma^{\prime}$ precipitates after thermal exposure within $50 \mathrm{~h}$ shows a similar cuboidal shape [Fig. 2(a, b)]. After thermal exposure of 100 to $300 \mathrm{~h}$, the cuboidal $\gamma^{\prime}$ precipitates gradually coarsened into rafts aligned along the $<100>$ direction [Figs. 2(c-e)]. The rafting morphology developed completely after $500 \mathrm{~h}$ of thermal exposure 

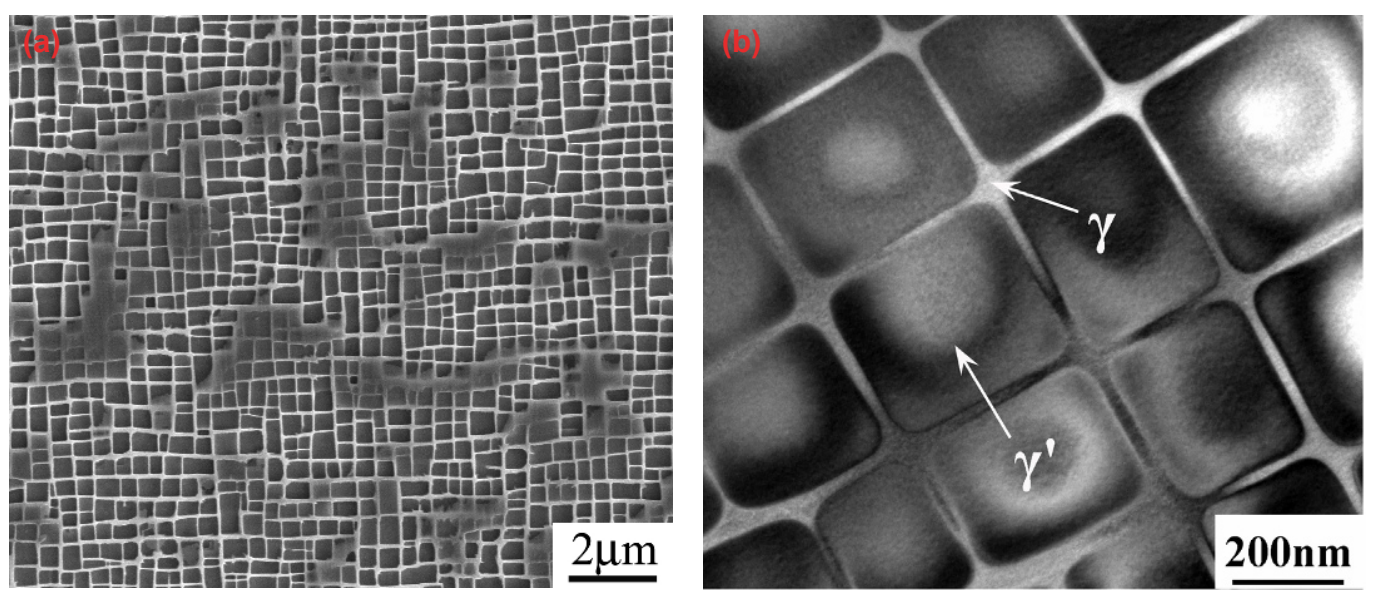

Fig. 1: SEM (a) and TEM (b) images of microstructure of DD11 alloy after full heat treatment
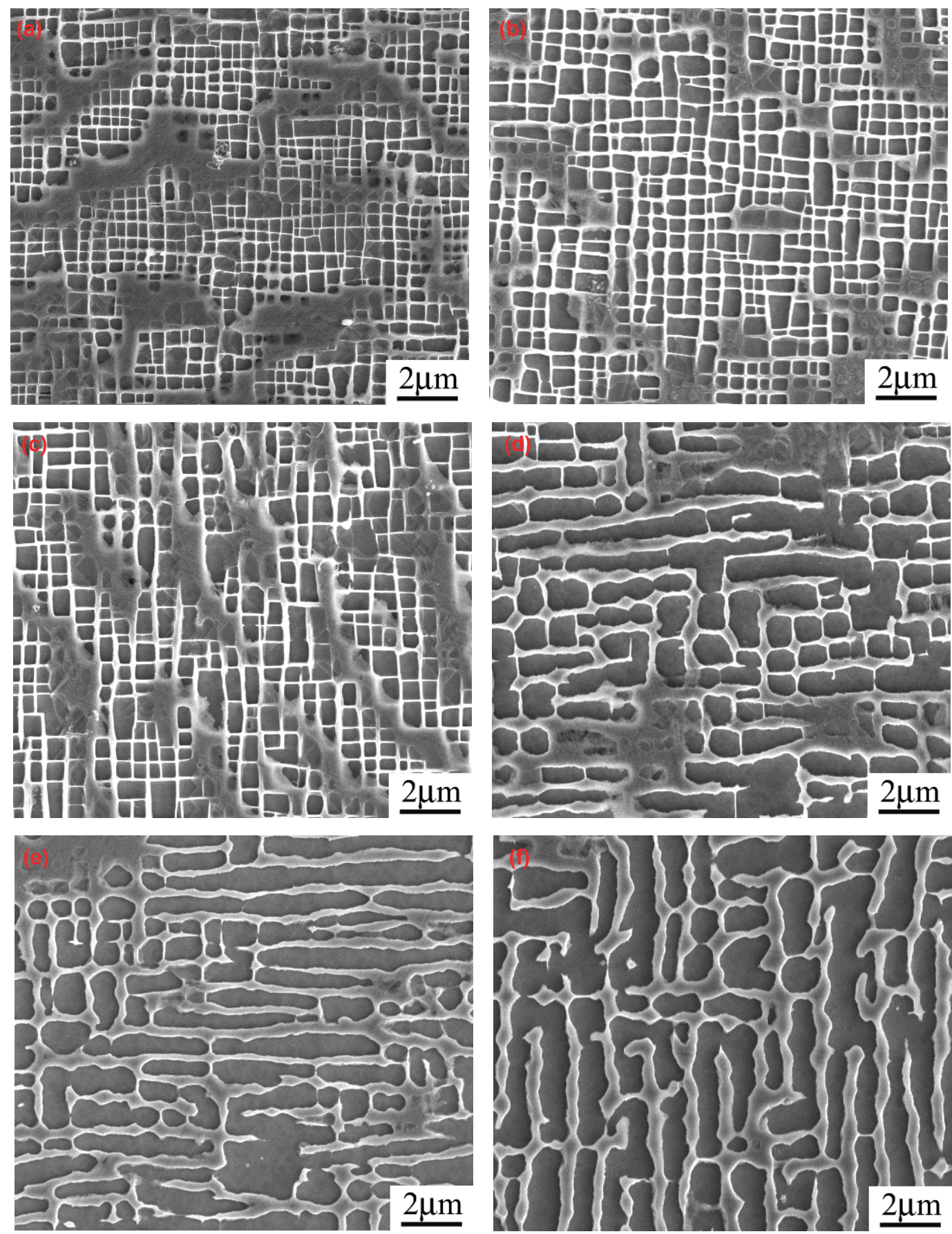

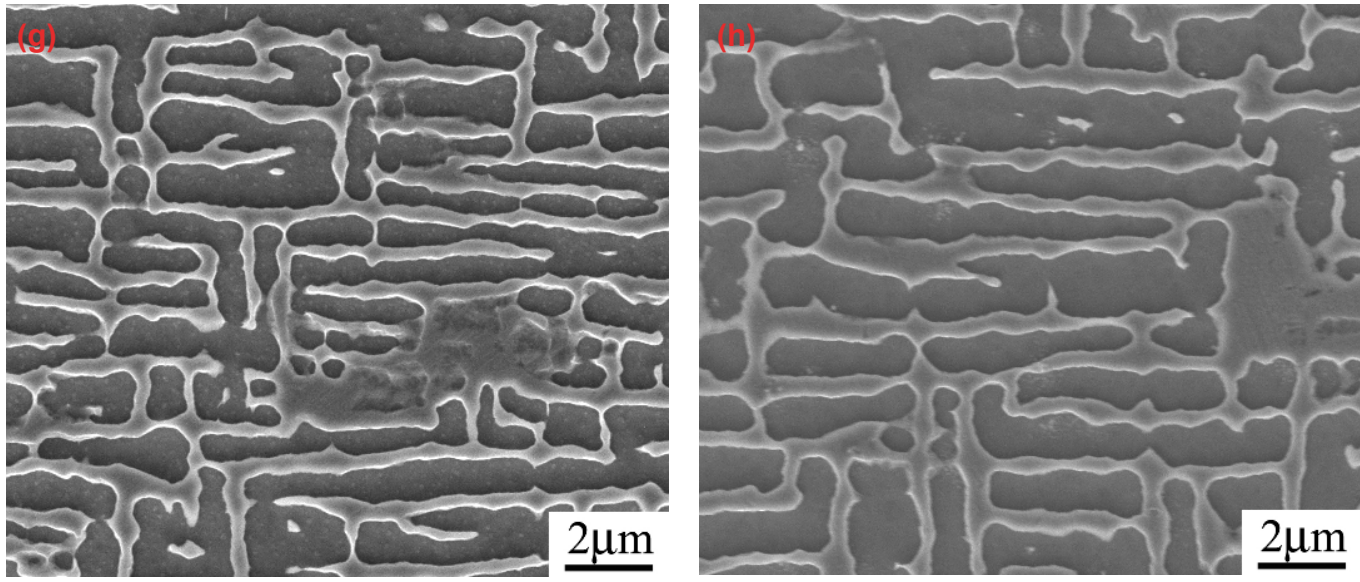

Fig. 2: Microstructure of DD11 alloy after thermal exposure at $1,070^{\circ} \mathrm{C}$ for different times: (a) $20 \mathrm{~h}$; (b) $50 \mathrm{~h}$; (c) $100 \mathrm{~h}$; (d) $200 \mathrm{~h}$; (e) $300 \mathrm{~h}$; (f) $500 \mathrm{~h}$; (g) $1000 \mathrm{~h}$; (h) 3,000 h

[Fig. 2(f)], and then remained nearly unchanged when the exposure time was prolonged to 3,000 h [Fig. 2(g, h)].

The volume fraction of $\gamma^{\prime}$ phase and dimensions of $\gamma^{\prime}$ and $\gamma$ phases during thermal exposure at $1,070{ }^{\circ} \mathrm{C}$ are shown in Fig. 3 . It demonstrates that the $\gamma^{\prime}$ phase volume fraction remained stable within $50 \mathrm{~h}$, declined gradually from 100 to $500 \mathrm{~h}$, and then reduced very slowly after $500 \mathrm{~h}$ thermal exposure. The size of the $\gamma^{\prime}$ phase and the width of the $\gamma$ channel show similar trends. The dimensions of the $\gamma^{\prime}$ and $\gamma$ phases increased slowly after thermal exposure for $50 \mathrm{~h}$, then increased faster from 100 to 500 $\mathrm{h}$, and then remained stable with increasing thermal exposure time up to $3,000 \mathrm{~h}$.

The $\gamma / \gamma^{\prime}$ interfacial energy was the driving force for the coarsening of the microstructure. The Young's modulus of nickel superalloy is the lowest in the $<100>$ direction, which results in the low strain energy $\{100\}$ crystal plane. The Ni-based single-crystal superalloys contain a large amount of refractory elements, in particular Re and W, with lower diffusion coefficients and larger atomic radii, which influence the process of diffusion and the misfit stress of the $\gamma / \gamma^{\prime}$ phase. This leads to directional diffusion flow ${ }^{[12,13]}$ and the formation of $\gamma^{\prime}$ rafts aligned along the $<100>$ direction during thermal exposure.

Theoretical studies on the coarsening behavior of $\gamma^{\prime}$ phase in

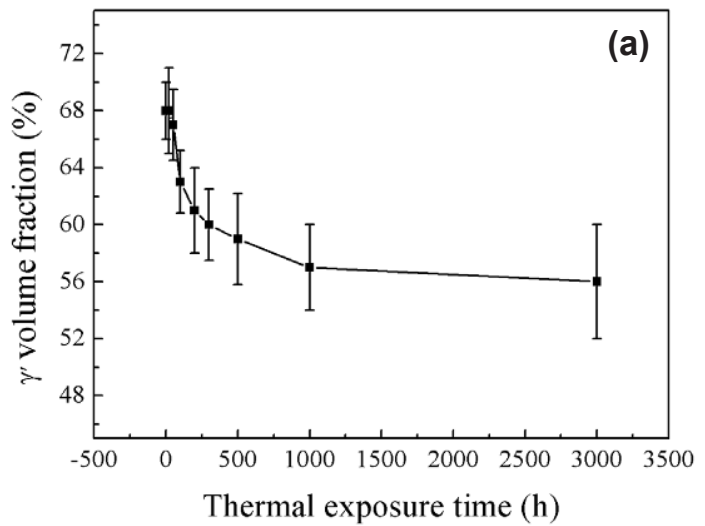

superalloys at elevated temperature have been widely conducted based on classic Lifshitz-Slyozov-Wagner (LSW) coarsening theory of Ostwald ripening:

$$
r^{3}-r_{0}^{3}=k t
$$

where $r$ and $r_{\mathrm{o}}$ are the mean radius of $\gamma^{\prime}$ phase at times $t$ and $t_{\mathrm{o}}$, respectively, and the constant $k$ is the coarsening rate coefficient. When $T>0.6 T_{\mathrm{M}}$ (where $T_{\mathrm{M}}$ is the melting point of the superalloy), the growth and coarsening of $\gamma^{\prime}$ phase are in favor of the dislocation motion. The dislocation structures of single-crystal superalloy DD11 subjected to long-term thermal exposure at $1,070{ }^{\circ} \mathrm{C}$ for $50,200,500$ and $3,000 \mathrm{~h}$ are shown in Fig. 4. Figure 4(a) shows the dislocation structure after thermal exposure for $50 \mathrm{~h}$ : there were a few dislocations. After $200 \mathrm{~h}$ [Fig. 4(b)], the number of dislocations deposited at the $\gamma / \gamma^{\prime}$ interface increased. After $500 \mathrm{~h}$, the dislocation network appeared in the $\gamma$ matrix [Fig. 4(c)], and after 3,000 h [Fig. 4(d)], the morphology of the dislocation network remained roughly constant. Without the external stress, the misfit stresses would be relieved by dislocation network to promote the rafting process ${ }^{[14]}$. When the dislocation network formed, the cuboidal $\gamma^{\prime}$ precipitates disappeared. Once the rafted structure had developed completely, its morphology remained almost unchanged as the thermal exposure time was prolonged.

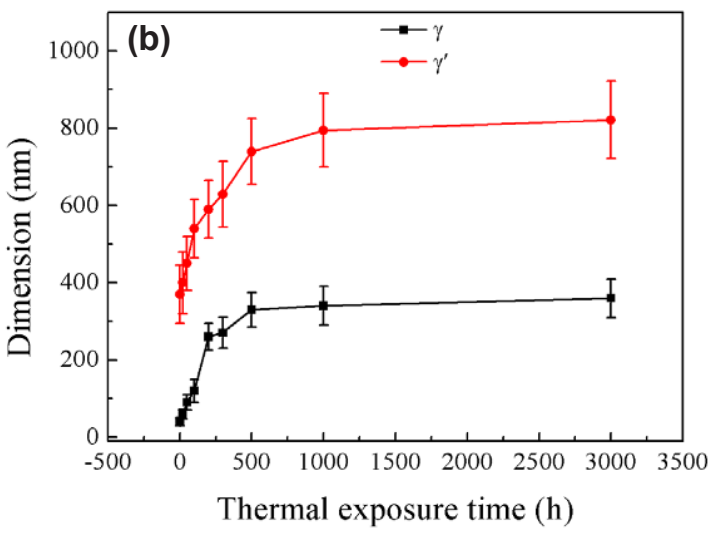

Fig. 3: Volume fraction of $\gamma^{\prime}$ phase (a) and dimension of $\gamma$ and $\gamma^{\prime}$ phases (b) after thermal exposure at $1,070^{\circ} \mathrm{C}$ for different times 

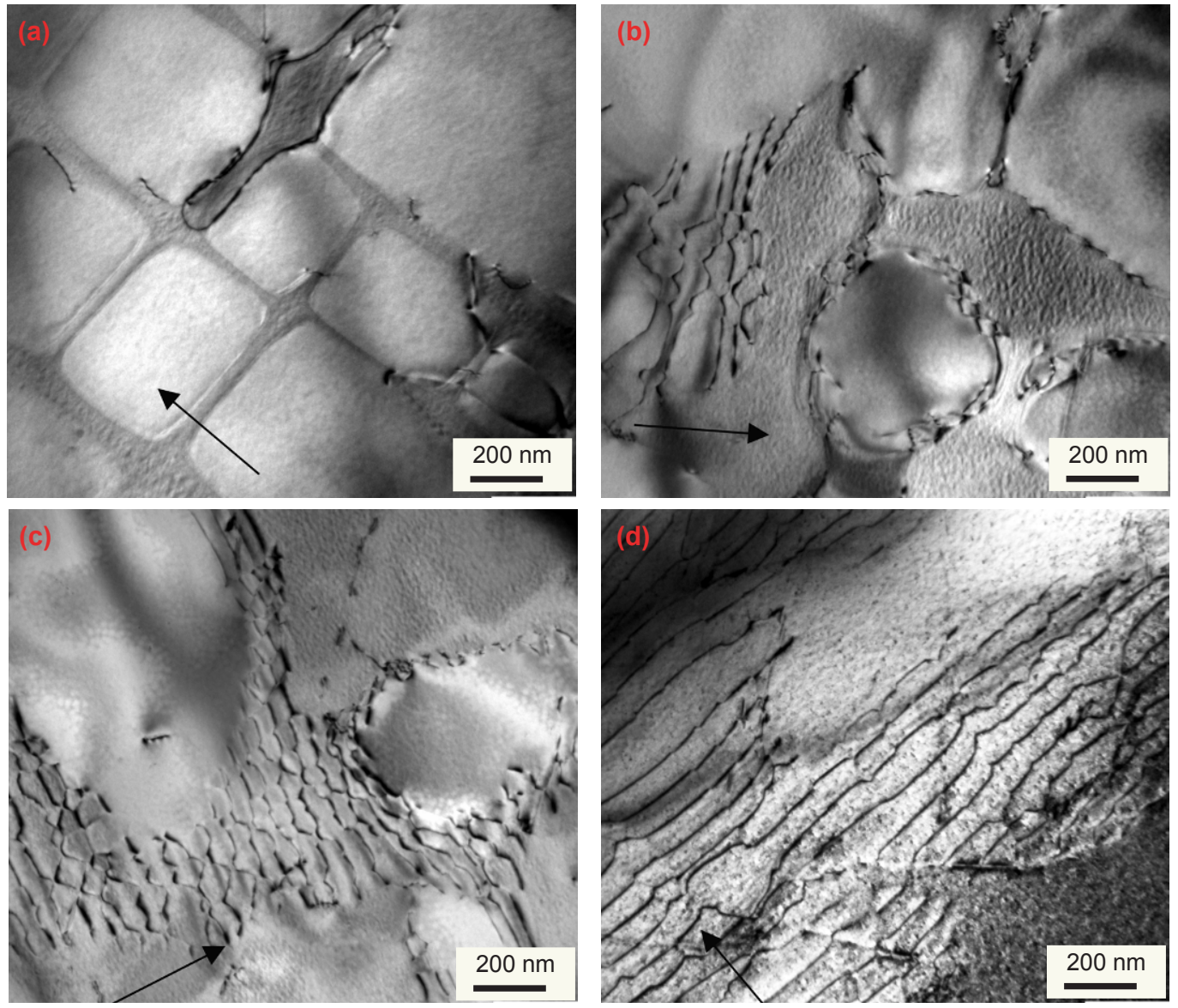

Fig. 4: Dislocation morphology of DD11 after thermal exposure at $1,070^{\circ} \mathrm{C}$ for different times: (a) $50 \mathrm{~h}$; (b) $200 \mathrm{~h}$; (c) $500 \mathrm{~h}$; (d) 3,000 h. B = [001], g= 020

\subsection{Stress rupture properties}

The stress rupture lives at $1,070^{\circ} \mathrm{C} / 140 \mathrm{MPa}$ of $\mathrm{DD} 11$ subjected to long-term thermal exposure at $1,070{ }^{\circ} \mathrm{C}$ for different times are shown in Fig. 5. The rupture life increased significantly after short exposure for $50 \mathrm{~h}$ but dropped dramatically when the exposure time was prolonged to $500 \mathrm{~h}$, and decreased slowly after exposure for further extended times. The stress rupture fractures are shown in Fig. 6. The rupture surfaces are mainly characterized by square-shaped dimples, which indicate that the samples displayed an almost ductile fracture mode consisting of square-like facets parallel $\{100\}$ planes.

The mechanical properties of Ni-based single-crystal are affected by the size and morphology of $\gamma^{\prime}$ precipitate. It has been shown that the optimum $\gamma^{\prime}$ size leads to the best hightemperature strengthening of Ni-based superalloys with the $\gamma / \gamma^{\prime}$ two-phase microstructure with cuboidal $\gamma^{\prime}$ precipitates, because $\gamma^{\prime}$ sizes that are too small or too large would favor Orowan looping or the precipitate shearing mechanism, respectively ${ }^{[15]}$. During thermal exposure, the average size of the $\gamma^{\prime}$ precipitate increased gradually from $370 \mathrm{~nm}$ after full heat treatment to $450 \mathrm{~nm}$ after $50 \mathrm{~h}$, and the $\gamma^{\prime}$ precipitate remained cuboidal. The cuboidal $\gamma^{\prime}$ precipitates with slightly increased size are probably the reason for the best stress rupture properties observed in DD11 after $50 \mathrm{~h}$ of thermal exposure. With the prolongation of the exposure time, the width of $\gamma$ channels increased gradually and the morphology of cuboidal precipitates gradually changed into a rafting structure.

The changes of the precipitate size and the matrix channel width have several effects on the mechanical properties. The precipitates are still coherent with the cuboidal morphology, and the coarsening plate-like structure indicates a loss of coherency at the $\gamma / \gamma^{\prime}$ interfaces and a subsequent reduction of the misfit stress, so the precipitation phase strengthening effect is reduced.

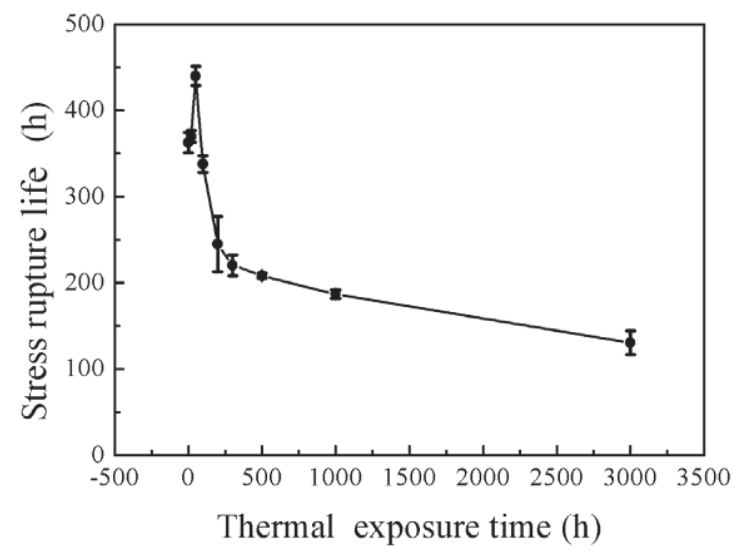

Fig. 5: Stress rupture lives at $1,070^{\circ} \mathrm{C} / 140 \mathrm{MPa}$ of DD11 after subjected to thermal exposure at $1,070^{\circ} \mathrm{C}$ for different times 

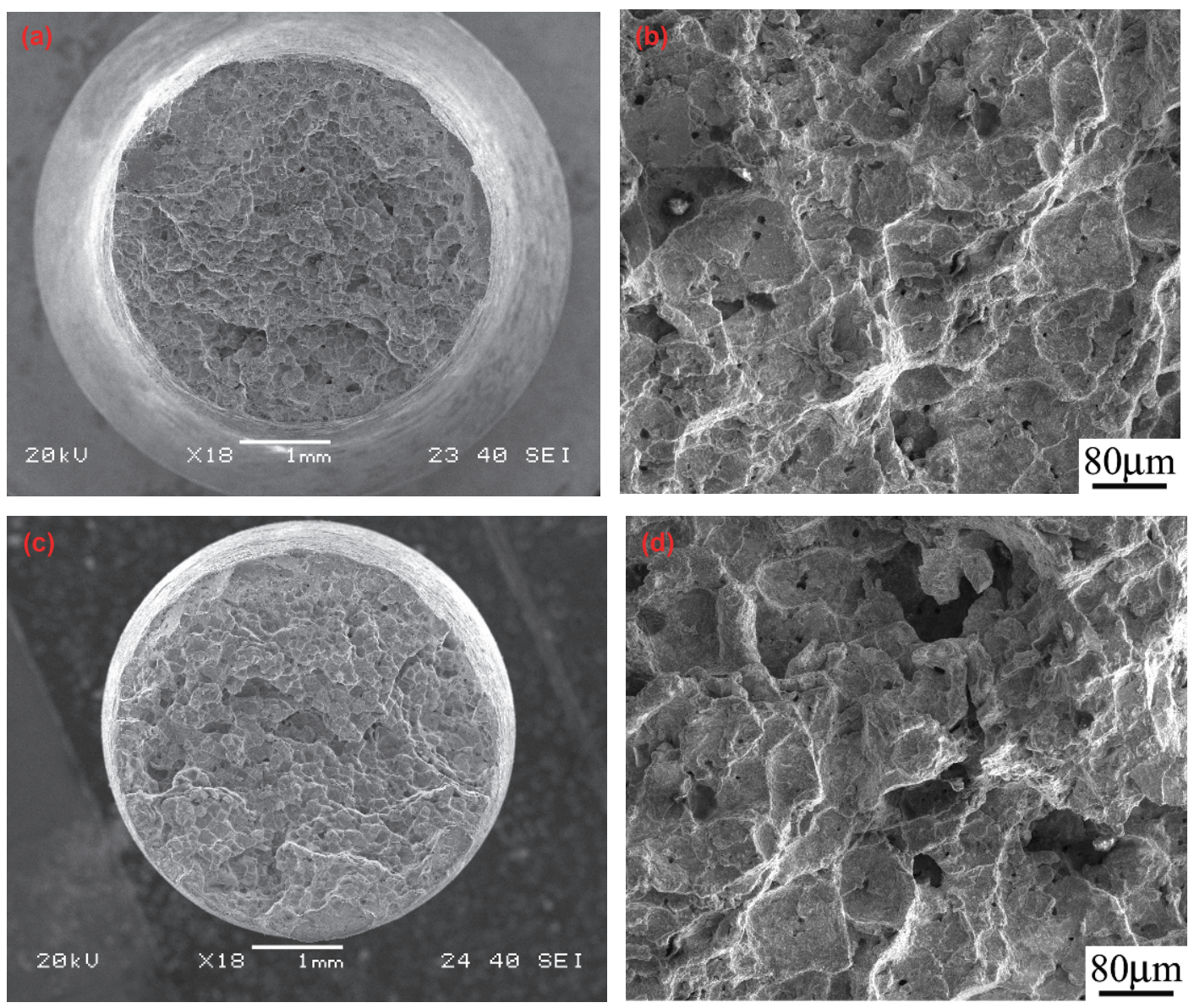

Fig. 6: SEM images of stress rupture fracture: (a, b) initial condition; (c, d) after thermal exposure at $1,070{ }^{\circ} \mathrm{C}$ for $1,000 \mathrm{~h}$

The precipitate shearing process becomes easier with the release of misfit stress ${ }^{[16]}$. The Orowan threshold $\tau$ is inversely proportional to the channel width:

$$
\tau=\frac{G B}{\lambda}=\sqrt{\frac{2}{3}} \frac{G B}{h}
$$

where $G$ is the shear modulus, $B$ is the Burgers vector, $\lambda$ is the largest channel dimension in the slip plane, and $h$ is the actual matrix channel width along the cube direction. It implies that the stress for the dislocation to pass through $\gamma$ channel would reduce as the $\gamma$ channel width increases, so a decrease of Orowan stress will occur during coarsening and lead to an increased matrix slip rate. Therefore, the stress rupture lives degraded with the coarsening of $\gamma^{\prime}$ particles and widening of the $\gamma$ channel after thermal exposure for 50 to $500 \mathrm{~h}$, while later, the stress rupture properties dropped very slowly since the coarsening microstructure was approximately stable.

\section{Conclusions}

(1) The $\gamma / \gamma^{\prime}$ two-phase microstructure of single-crystal superalloy DD11 gradually coarsened under thermal exposure at $1,070{ }^{\circ} \mathrm{C}$ from 20 to $3,000 \mathrm{~h}$. The cuboidal $\gamma^{\prime}$ precipitates remained cuboidal after thermal exposure for $50 \mathrm{~h}$ and then gradually changed into an irregular raft-like morphology by particle coalescence. After thermal exposure for $500 \mathrm{~h}$ and longer, the morphology of the microstructure remained approximately stable.

(2) The stress rupture lives of DD11 under conditions of $1,070{ }^{\circ} \mathrm{C}$ and $140 \mathrm{MPa}$ firstly increased after a short exposure time of $50 \mathrm{~h}$, and then decreased significantly with prolongation of the exposure time to $500 \mathrm{~h}$, followed by a slow decrease as thermal exposure time extended from 500 to $3,000 \mathrm{~h}$.

(3) After thermal exposure at $1,070{ }^{\circ} \mathrm{C}$, the stress rupture lives did not decline when the $\gamma^{\prime}$ remained cuboidal but dropped along with the $\gamma^{\prime}$ precipitates coarsening process. After the rafted microstructures had formed completely, the stress rupture lives degraded very slowly.

\section{References}

[1] Sun Xiaofeng, Jin Tao, Zhou Yiwei, et al. Research progress of Ni-based single crystal superalloys. Rare Metals Letters, 2012, 31(12): 1-11 (In Chinese).

[2] Jin Tao, Zhou Yiwei, Wang Xinguang, et al. Research process on microstructural stability and mechanical behavior of advanced $\mathrm{Ni}$-based single crystal superalloys. Acta Metallurgica Sinica, 2015, (10): 1153-1162 (In Chinese).

[3] Murakumo T, Kobayashi T, Koizumi Y, et al. Creep behaviour of $\mathrm{Ni}$-base single-crystal superalloys with various $\gamma^{\prime}$ volume fraction. Acta Materialia, 2004, 52(12): 3737-3744.

[4] Liu Lirong, Chen Haijun, Jin Tao, et al. Effect of $\gamma^{\prime}$ formation and strengthening elements on microstructures and stress rupture property of single crystal super-alloys. China Foundry, 2010, 
07(3): 265-269.

[5] Wen Tao, Li Jinguo, Liu Lirong, et al. Effect of long-term aging on microstructure evolution and stress rupture properties of ni-based single crystal superalloy. Rare Metal Materials \& Engineering, 2012, 41(2): 230-234.

[6] Zhang Heng, Liang Yunfei, Ru Yi, et al. Effect of thermal exposure on the stress-rupture life and microstructure of a low Re-containing single crystal alloy. Progress in Natural Science: Materials International, 2015, 25(1): 84-89.

[7] Veron M, Brechet $Y$, Louchet F. Directional coarsening of nickel based superalloys: driving force and kinetics. Superalloys, 1996: 181-190.

[8] Nguyen L, Shi Rongpei, Wang Yunzhi, et al. Quantification of rafting of $\gamma^{\prime}$ precipitates in $\mathrm{Ni}$-based superalloys. Acta Materialia, 2016, 103: 322-333.

[9] Lapin J, Gebura M, Pelachová T, et al. Coarsening kinetics of cyboidal y precipitates in single crystal nickel base superalloy CMSX-4. Kovove Materialy, 2008, 46(6): 313-322.

[10] Acharya M V, Fuchs G E. The effect of long-term thermal exposures on the microstructure and properties of CMSX10 single crystal Ni-base superalloys. Materials Science and Engineering: A, 2004, 381(1-2): 143-153.
[11] Luo Yushi, Zhao Yunsong, Liu Zhiyun, et al. Effect of heat treatment on microstructures and stress rupture properties of a second generation Ni-based single crystal DD11. Journal of Chongqing University (Natural Science Edition), 2016, 39(3): 43-50 (In Chinese).

[12] Milhet $X$, Arnoux M, Cormier J, et al. On the influence of the dendritic structure on the creep behavior of a Re-containing superalloy at high temperature/low stress. Materials Science \& Engineering A, 2012, 546(5): 139-145.

[13] Reed R C, Cox D C, Rae C M F. Kinetics of rafting in a single crystal superalloy: effects of residual microsegregation. Materials Science and Technology, 2007, 23(8): 893-902.

[14] Epishin A, Link T. Mechanisms of high-temperature creep of nickel-based superalloys under low applied stresses. Philosophical Magazine, 2004, 84(19): 1979-2000.

[15] Reed R. The superalloys. New York, Cambridge University Press, 2006: 152-153.

[16] Reed R C, Cox D C, Rae C M F. Damage accumulation during creep deformation of a single crystal superalloy at $1150^{\circ} \mathrm{C}$. Materials Science and Engineering: A, 2007, 448(1-2): 88-96.

The work was funded by the National High Technology Research and Development Program (No. 2012AA03A513). 